\title{
Study on Construction of Embedded Bolt Sleeve's Precision in Massive Concrete
}

\author{
Chongge Wang ${ }^{1,2}$,Jiachuan Liu ${ }^{1}$ \\ ${ }^{1}$ College of Civil Engineering and Architecture, Shandong University of Science \\ and Technology,Qingdao266590,China; \\ ${ }^{2}$ Geotechnical and Structural Engineering Research Center, Shandong \\ University,Jinan 250000,China
}

\begin{abstract}
In recent years, with the coal mine construction expanded, the hoisting ability has had corresponding increase and the requirement for the quality of equipment foundation has become increasingly high; especially the requirement for embedded casing's positional accuracy in the massive concrete is demanding, because it is directly related to hoisting and the installation of equipment. Embedded bolt sleeve's precision of the massive concrete has so far become a subject worthy of our study.
\end{abstract}

Keywords : embedded casing, mine construction, massive concrete.

\section{Introduction}

The paper discusses the construction process of embedded casing in the massive concrete, which belongs to the Inner Mongolia Bayangaole mine’s main shaft elevator. The drum diameter of the mine is the second one in our country which has 5 meters. Therefore, it sets high requirements for the foundation's concrete quality and embedded casing's positional accuracy. Taking into account the factors of construction quality, safety, period, cost, civilization construction and the characteristics of the project, we worked out the best method of construction. We planned to pour the winch foundation and floor plate in one time and then the embedded bolt sleeve 
would be overall fixed after the foundation template was reinforced, which could effectively solve the problem of massive concrete construction joint.

\section{Construction scheme}

Material preparation: The project selects Po42.5 normal Portland cement which has such qualities as low alkali, relatively stable performance index and sufficient supply. The project chose the good gradation-crushed stone or gravel whose maximum diameter is no bigger than $40 \mathrm{~mm}$, and the mud content was strictly controlled. With certificates and test report, steel varieties and specifications meet the design requirements. The choice of admixtures, based on construction demand, was determined through testing, which should have a product certificate.

The construction was the Inner Mongolia Bayangaole mine's main shaft elevator room, which reinforced concrete bent structure with 27 meters long by 23 meters wide.

According to the layout characteristics of engineering and the convenience of operations and the construction efficiency, we had made out the technological process as follows: use the large panel formwork opposite stretching inclined pull bolt reinforcement construction, build in embedded bolt sleeve, use steel bar to whole fix.

The construction was carried out according to the following stages:

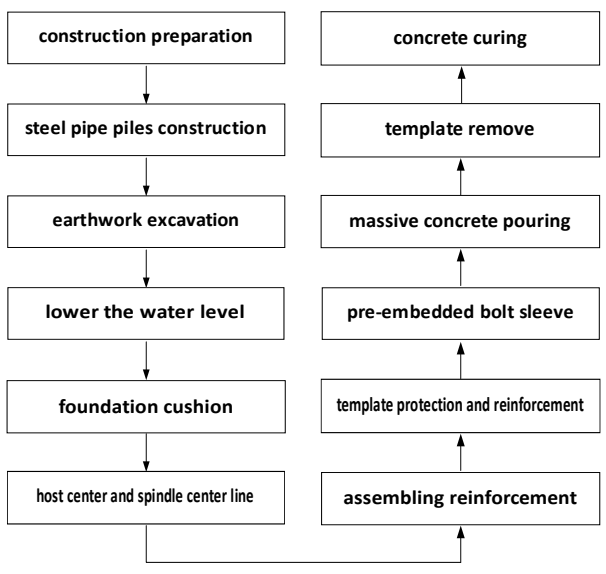

Fig.1 The construction flow chart.

\section{Construction method}

Since the hoist building was close to the wellhead, in order to ensure the safety of construction, we used the steel pipe pile near the wellhead. Because the underground water level was high, the foundation depth below the surface of the water about 2 meters and the dewatering construction was needed.

When completing the cushion construction, we firstly put the hoist center line and the spindle center line which were in hoist way and then re-inspected. After being checked, all the other processes could use the two lines as the reference for the construction, which 
could guarantee the foundation of the hoist and the positional accuracy of embedded bolt sleeve.

As the foundation was rather high, we should pay attention to the accurate location when assembling reinforcement, and set aside the position of the pre-embedded bolt sleeve so as to protect the template and avoid cutting reinforced when we were installing the casings.

Template was fixed by using $\Phi 12$ opposite stretching steel bar, interval 300, horizontal and vertical arrangements, and steel pipe was used to prop open from inside and outside to ensure the panel formwork fixed. Embedded D133 bolt sleeve, and put the bolt sleeve on the embedded position roughly. Then we fixed the bolt sleeve on the precision position and used the steel bar weld reinforcement from the upper and lower. We had the bolt sleeve welded and fixed on the template to prevent sleeve from moving around (detailed in the following figures).

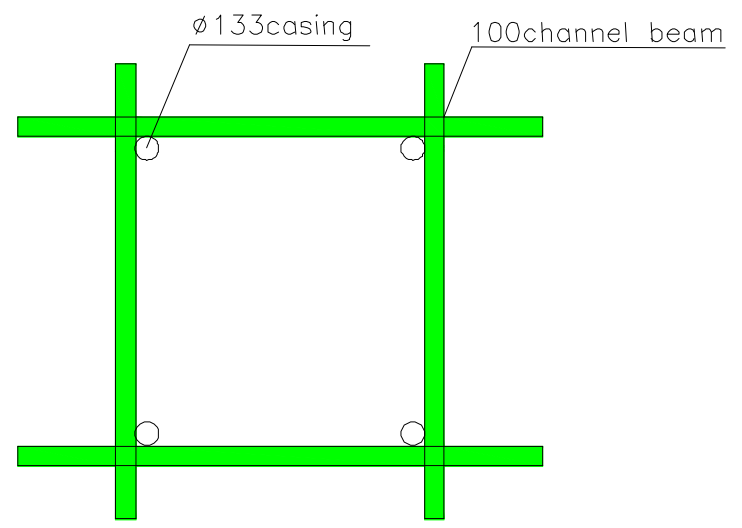

Fig.2 Schematic plan of the sleeve fix.

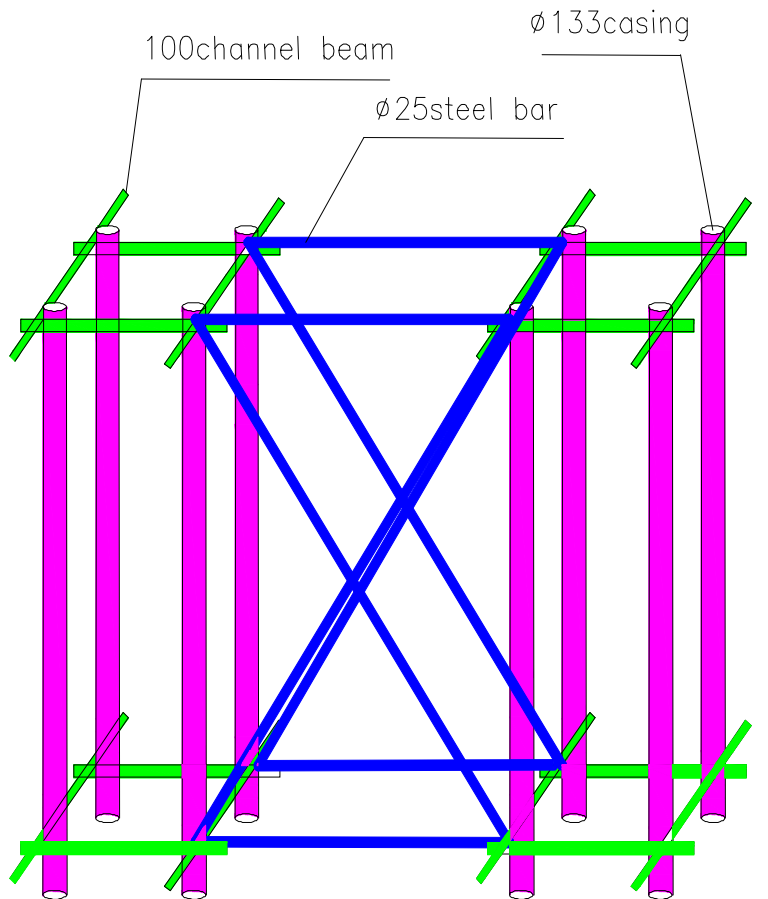

Fig.3 Schematic of the embedded casing fixed relative position.

We used layered pouring in concrete placement, with 500 meters for a step, around the periphery of the foundation pouring gradually. Concrete pouring cannot be pointed directly at the bolt sleeve position, which was to avoid the 
impact caused by the displacement of concrete pouring. Vibrating was only around the casings in order that it could not only ensure the compactness of concrete, but also ensure that casings couldn't shift. After template removed, the concrete should be covered with plastic film and watering maintenance should be undertaken in time.

\section{Conclusions}

The advantages of utilizing embedded bolt sleeve's precision in the massive concrete in the Inner Mongolia Bayangaole mine's main shaft elevator are as follows:

(1) Pouring the winch foundation and floor plate in one time can ensure the integrity of the hoist concrete foundation.

(2) Template was fixed by using opposite stretching steel bar from horizontal and vertical arrangements, and steel pipe could be used to prop open from inside and outside to ensure that sleeve could not move around.

(3) Integral pouring concrete construction could not only save time and labor and cost consumption, but also be conducive to the improvement of economic benefit.

(4) The overall template construction improved the appearance quality of concrete and the reuse of template, saved a lot of wood.

\section{Acknowledgements}

This research was supported by grants from China Postdoctoral Science Foundation(No:20080440171) and Shandong Province Postdoctoral Science Foundation

(No:200801006)

\section{References}

[1]Jianghua Wang. Construction technology of winch foundation in Xin'an mine[J].Coal science \& technology magazine. 2008,4:82-83.

[2]Yuwen Chen. Construction technology of caster foundation [J]. Jiangsu

Metallurgy. 2008, 36(1):49-52.

[3]Jiayan Ma. Discussion on the construction technology of winch foundation [J]. Shanxi Architecture. 2008, 34(1):166-167

[4]Puming Xie, Jianmin Zheng. Improvement of construction workmanship for embedded bolt holder [J].Building Construction. 2011, 33(2): 118-119.

[5]Yiming Yang, Jian Liu, Cao Yueqin, et al. Positioning method for embedded bolt sleeve in concrete structure[P]. China:102322145, 2009-09-23.

[6]Qingwei Wang, Mingquan $\mathrm{Wu}$, et al. A concrete pre-embedded bolt sleeve positioning mechanism $[\mathrm{P}]$. China: 201170420, 2008-12-24. 